\title{
Biotope Mapping in Wetlands Using High-Resolution Satellite Images
}

\author{
Ahmet Cilek ${ }^{1}$, Suha Berberoglu ${ }^{1}$, Cenk Donmez $^{1}$ \\ 1. Landscape Architecture Department, Cukurova University, TURKEY, Adana, E-mail: acilek@cu.edu.tr
}

\begin{abstract}
The paper introduces a contextual investigation for the utilization of remote sensing \& GIS data with regards to biotope mapping of Cukurova Delta. Akyatan Lagoon is the largest lagoon lake in Turkey and has a high biodiversity particularly in and around lagoon system of Cukurova Delta.
\end{abstract}

Keywords - biotope mapping, Remote sensing, land use/cover, Wetlands, CORINE

\section{Introduction}

Remote sensing has long been identified as a innovation technology for supporting the advancment of biotope maps over large areas [1]. "Biotope" is the living environment of both plants and animals [2]; physical environment of the organism or the community of organisms [3,4]. In general, "biotope" is used for characterizing the natural landscape. Wetlands are the territories that have significant effects and functions on protecting human life, adjust to nature, and organic assortment, other than being potential misuse sources. Observing the adjustments in these complex areas is vital to study for information gathering and right making arrangements for the future. Remote sensing and Geographic Information System are being increasingly used for environmental studies such as biotope mapping and habitat monitoring. Akyatan Lagoon one of the most critical wetlands in Turkey has been facing serious threats from agricultural applications in recent years. In this study, seasonal monitoring in wetlands system is determined by using remotely sensed data and Geographic Information Systems (GIS) using SPOT satellite images. The research method is based on classifying and mapping biotopes in the study area.

\section{Materials \& Methods}

The Cukurova Delta is an internationally important coastal strip ecosystem and located at the Eastern Mediterranean coast of Turkey. The Delta encloses an area about $5000 \mathrm{~km}^{2}$ with 110 $\mathrm{km}$ coastal zone, includes Europe's largest natural sand dune ecosystems. The Delta is the largest coastal river basin in Turkey and formed by the sediments from Berdan, Seyhan and Ceyhan Rivers. However, the Delta is under risk of various activities (e.g., intensive agriculture, dune flattening, waste dumping, grazing, cutting and water pollution). This research was conducted to determine the spatial distribution of biotopes to understand the ecological process within the Cukurova Delta. For this purpose, the interaction between agricultural activities and; sand dune, salt marsh and salt meadow, forest with Pinus sp and afforestation areas was evaluated in a Mediterranean type agricultural plain (Fig.1). 


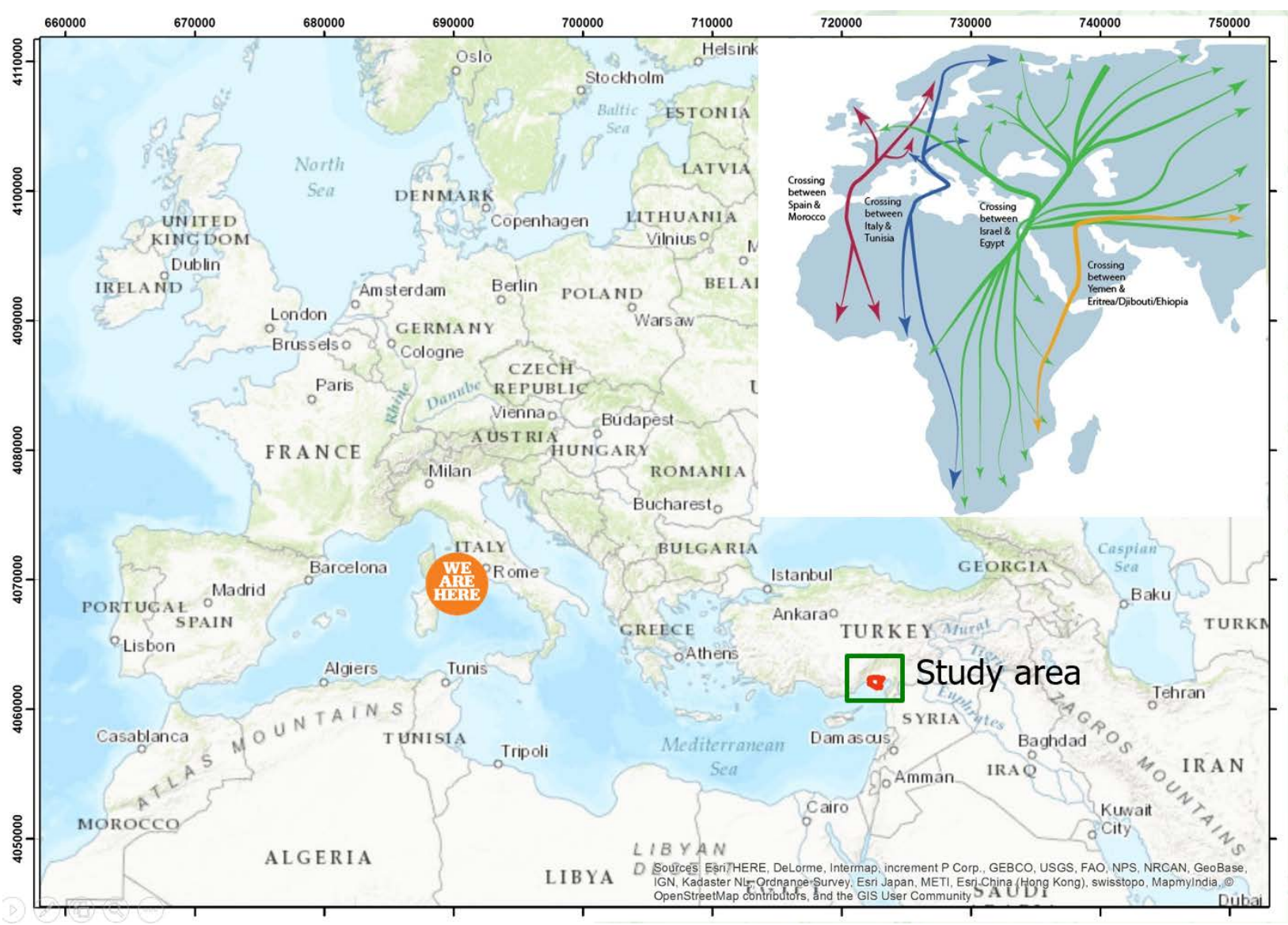

Fig.1. The location of the study area

\section{Remote sensing \& GIS datasets}

- SPOT6-7 2015: May, June, July, August, September and November

- Administrative borders

- Layer data set in SHAPE format

-- Forest

-- Settlements

-- Streets

-- Rivers

The CORINE Programme used in this study was established by the European Commission to create a harmonized geographical information system on the state of the environment in the European Community. The 'biotopes' inventory of sites of major importance for nature conservation was a priority topic [5] (Fig.2). 


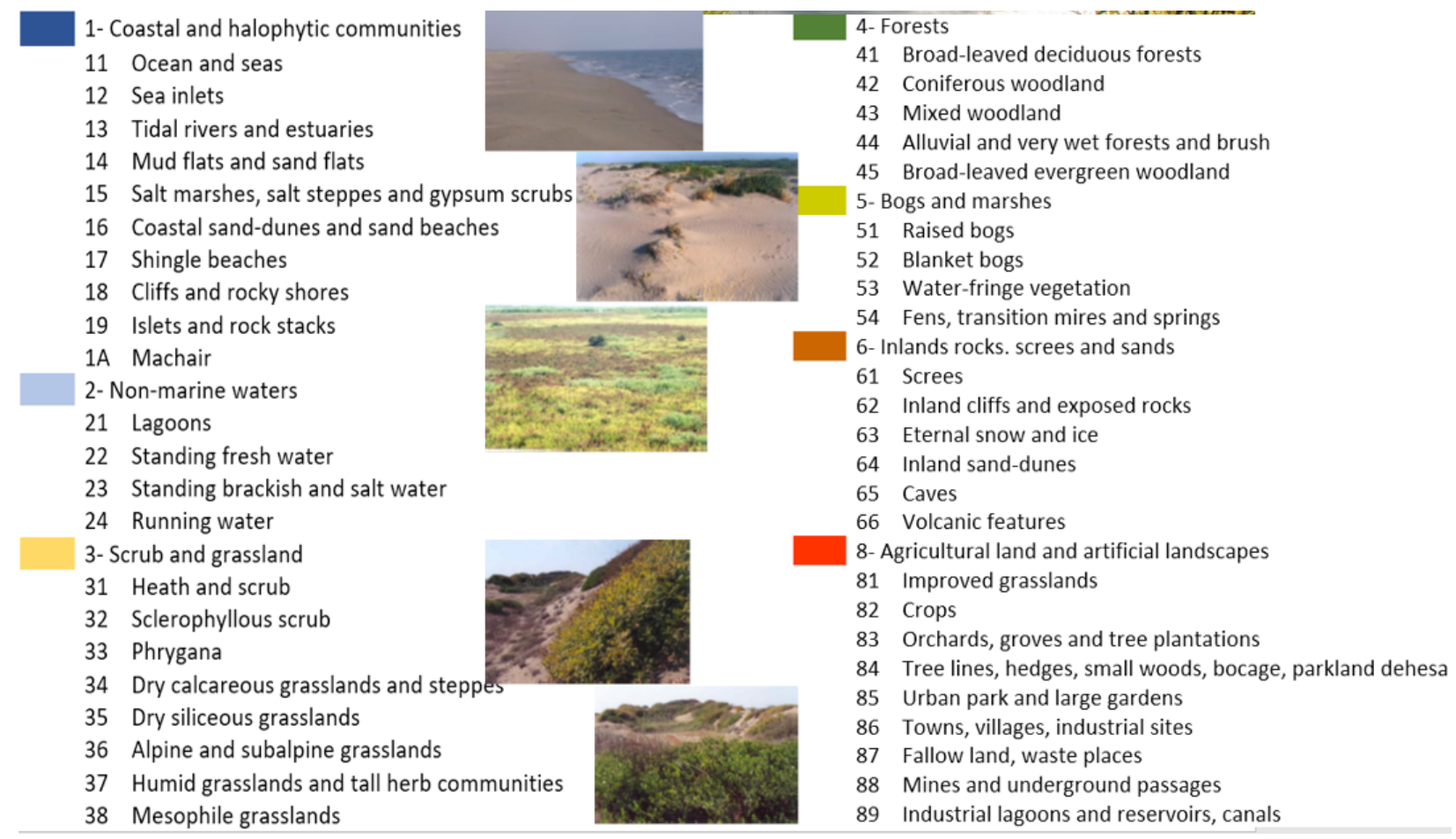

Fig.2. CORINE Biotope classification scheme

\section{Results}

The research method depends on classifying and mapping the biotopes in coastal side of Cukurova Delta. The natural biotope types compose coastal sand dunes, salt marshes, river beds, coastal woods, lakes and lagoons. This covers the range of techniques including, detection of marginal biotope where agricultural application threatens using multi-temporal satellite data together with object-based classification.

The outcomes of object-based classification showed good results in the study area. The training data selected all biotope classes assisted to classify other similar objects with the similar spectral characteristics. After the multiresolution segmentation, a set of classification tree were applied to the classification to classify all of the CORINE biotope classes within the SPOT data (Fig. 3).

\section{Object-based classification}

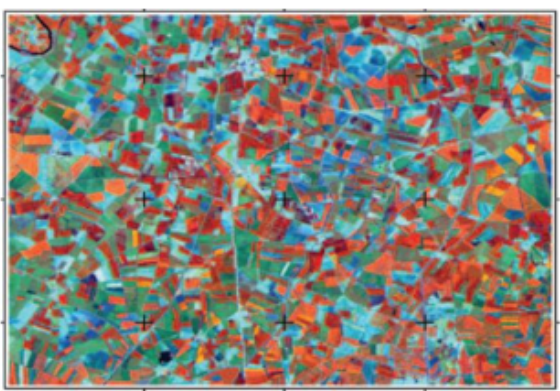

Color/shape parameters

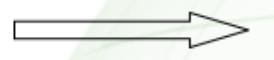

Scale Parameter

Fig.3. Segmentation process of the object-based classification

The classification process was a data homogenization, which means that the provided data sets had different projection types and orthorectify. Basically, there are three stages in objectbased classification as segmentation, classification and per field integration. An image was divided segments dependent on pixel spectral similarities, the structure of the image and surface texture characteristics (Fig.4.). 


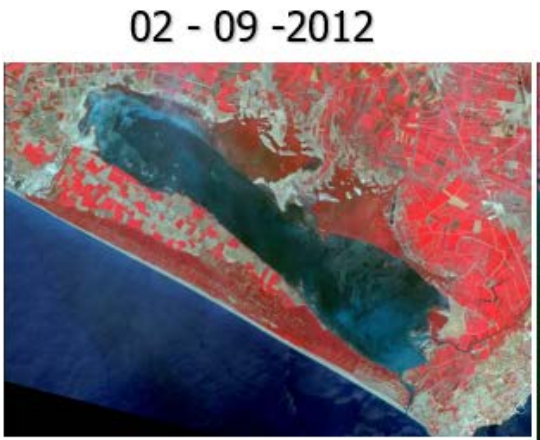

$18-07-2015$

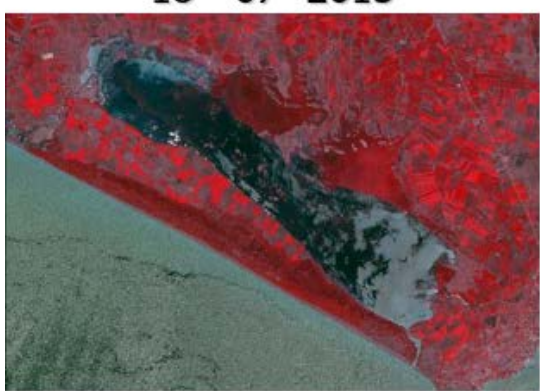

$16-05-2015$

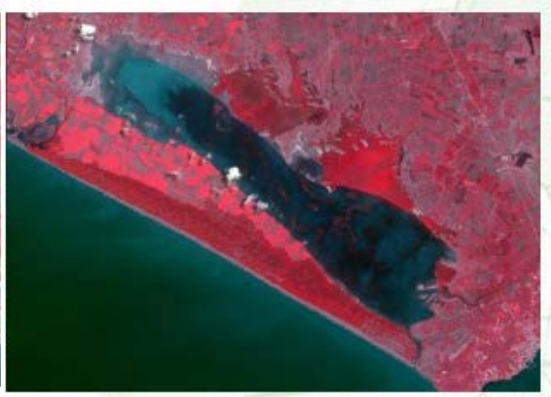

$16-09-2015$

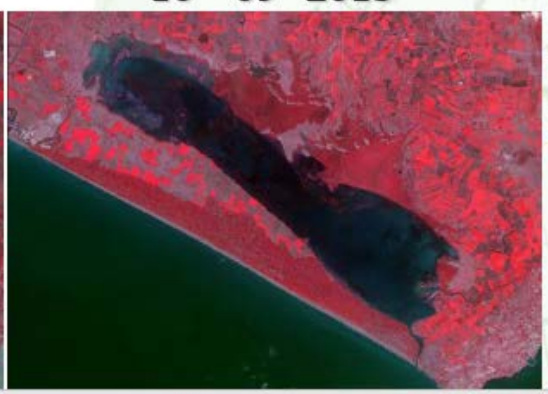

Fig.3. Spot 6-7 images

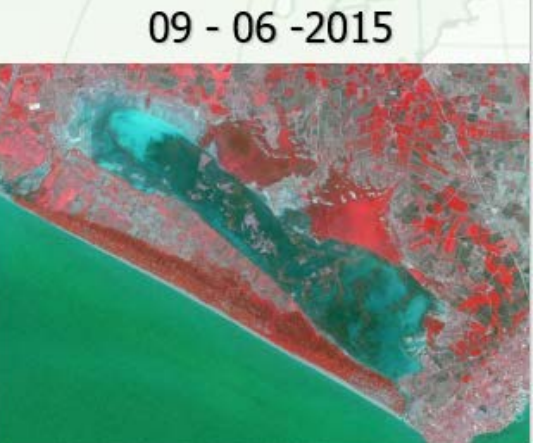

$19-11-2015$

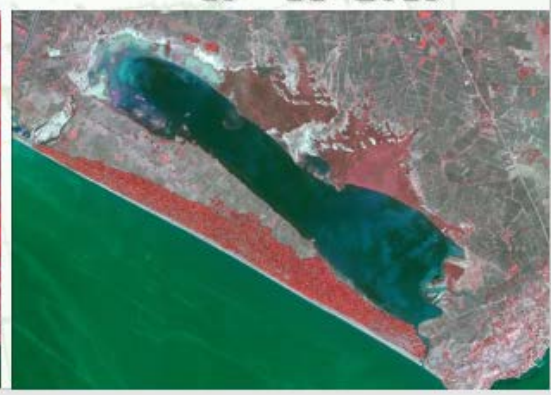

A database was formed in order to provide basis for ecological planning approach in urban areas by mentioning plant species found in each biotope (Fig.4).
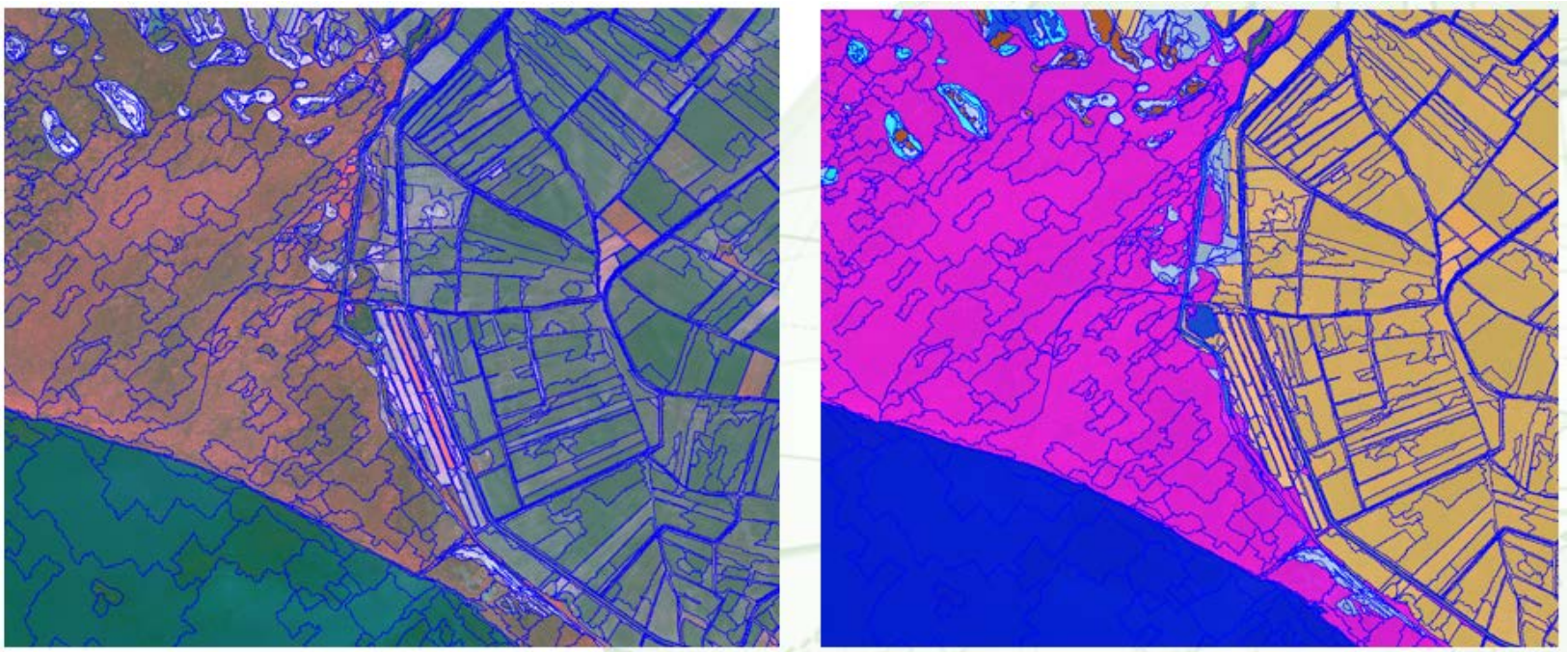

Fig.4. Object-based segmentation for fieldwork base maps

All CORINE Biotope classes were determined using object-based classification and mapped for the study area via Geographical information systems. Varieties in land use types and plant species combination were used as markers in determination of the regions that show environmental variety (Fig.5). 


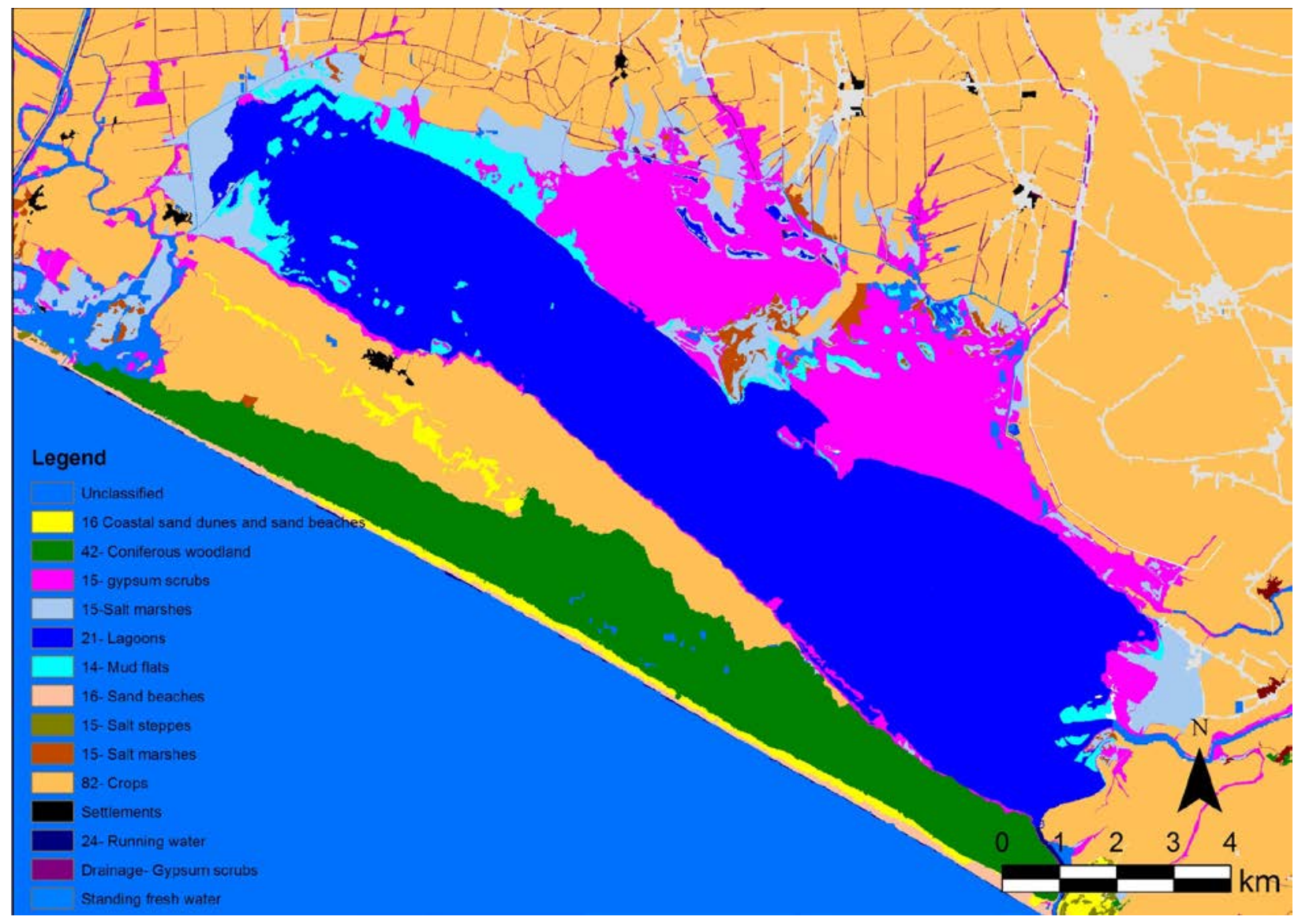

Fig.5. Biotope mapping of Akyatan Lagoon.

\section{Conclusion}

In this study, object-based classification showed that object-based classification results were highly accurate. Using this method, high resolution images have made it to distinguish each biotope class from one another. The kappa value was calculated as 0.95 , this value indicates that 95\% of the classes were estimated correctly. So, this classification method is suitable for biotope mapping from high resolution satellite images such important and complex biotopes.

\section{Acknowledgments}

This research has been supported by the Scientific and Technological Research Council of Turkey (Project ID:115Y063)

\section{References}

[1] Mcdermid, G.J., Franklin, S.E., LeDrew, E.F. 2005. Remote sensing for large-area habitat mapping. Physical Geography: Earth and Environment, Volume: 29 issue: 4, page(s): 449474

[2] Altan T, Bierhals E, Y1lmaz T (1988). Biotope mapping. Cukurova Agriculture Faculty, Supplementary Class Book No:14, Adana, Turkey, (in Turkish).

[3] Koseoglu M (1981). Landscape ecology studies and researches on the mapping of biotopes. Ege University Agriculture Faculty No: 442, (in Turkish).

[4] Yilmaz, B., Gulez, S. Kaya, L.G. 2010. Mapping of biotopes in urban areas: A case of the city of Bartın and its environs, Turkey. Scientific Research and Essays Vol. 5 (4), pp. 352365, 18 February, 2010 
[5] Moss, D., Wyat, B.K. The CORINE biotopes project: a database for conservation of nature and wildlife in the European community. Applied Geography, Volume 14, Issue 4, 327349. 